\title{
Esthetics and Dental Restorations
}

\section{Sorin Uram-Tuculescu*}

Assistant Professor, Department of Prosthodontics, School of Dentistry, Virginia Commonwealth University, USA

Dental esthetics as part of facial and body appearance can be probably regarded as common sense today, but this domain supports further characterization, considering at least a historical and social perspective. In order to do so, an examination of the evolution and levels of esthetic perception would be helpful.

Esthetics refers to the branch of philosophy dealing with beauty and taste. It can be regarded also as an artistic, anthropological, social and cultural dimension.

The roots of esthetics can be traced in ancient times, along with the earliest beginnings of art, but to describe it as a movement, we need to go back only in the $19^{\text {th }}$ century, when estheticism was documented in Europe. Also known as symbolism or decadence in France, it was an anti-Victorian reaction, emphasizing esthetic values over moral or social themes.

Why is it so important? Probably because more than $90 \%$ of our afferent stimuli are visual, and the not so old saying "what is beautiful is good" [1] was recently confirmed again: people with more attractive faces are assessed to be more successful, contended, pleasant, intelligent, sociable, exciting, creative and diligent [2]. Gruendel [2] also found that the most attractive faces (as rated by lay persons) do not exist in reality; but can be obtained by "morphing" (averaging) images, using graphic software.

Since in the post-modern society we are exposed to "perfection" via media, a question rises: how realistic can one be in their expectations?

"What is natural is beautiful" is probably an insufficient statement for some, because living in a world which is more and more artificial, one may want to keep up with the "ideal", as is constantly presented by media. As a consequence, significant body modification and esthetic enhancements are not uncommon in the developed world.

As for esthetic perception and characterization levels, we can refer to philosophers, artists, surgeons, dentists (the "professionals"), on one hand, and the public, on the other hand. An intermediary level, regarded as alternate connection between the two, would be the media, with its own agenda and recommendations.

The professional tier will always be ahead of the public in their definitions, assessment, and characterization.

Even though the ability to recognize beauty is considered innate, but modulated by individual preference, cultural bias, and time, it appears that lay raters in different locations are not significantly different in their assessment [3]. This is probably due to global migration [4], media, peers/community pressure.

Patients' perceptions generally differ from objective measures taken by professionals, as observed by dental practitioners, as well [57]. In terms of dental esthetics, lay persons recognize a large range of acceptability, as compared with dental professionals [8].

As professionals, we can probably consider treaties on beauty and ugliness like Umberto Eco, but at the end it boils down to what really our patients expect us to do for them.

Clinicians should use care in identifying ideal for their patients, because the last could be sensitized to unrealistic or unattainable goals [3].

To meet patient's esthetic representations at conceptual level, and satisfy their expectations at delivery, within the limitations of existing anatomy, disease, time and finances may not be an easy task, and in order to achieve that, knowledge of esthetic principles and trends would be critical.

\section{References}

1. Dion KK, Bersheid E, Walster E (1972) What is beautiful is good. J Persona Soc Psychol; 24: 285-290.

2. Gruendel M Beautycheck - Causes and Consequences of Human Facia Attractiveness (Summary)

3. Ker AJ, Chan R, Fields HW, Beck M, Rosenstiel S (2008) Esthetics and Smile Characteristics From the Layperson's Perspective: A Computer-Based Survey Study. JADA; 139: 1318-1327.

4. Population Reference Bureau 2010

5. de Grandmont P, Feine JS, Tache R, Boudrias P, Donohue WB, et al. (1994) Within-subject comparisons of implant-supported mandibular prostheses: psychometric evaluation. J Dent Res 73: 1096-1104.

6. Feine JS, Maskawi K, de Grandmont P, Donohue WB, Tanguay R,et al. (1994) Within-subject comparisons of implant-supported mandibular prostheses: evaluation of masticatory function. J Dent Res 73: 1646-1656.

7. Garrett NR, Kapur KK, Perez P (1996) Effects of improvements of poorly fitting dentures and new dentures on patient satisfaction. J Prosthet Dent 76: 403413

8. Springer NC, Chang C, Fields HW, Beck FM, Firestone AR, et al. (2011) Smile esthetics from the layperson's perspective. Am J Orthod Dentofacial Orthop: 139: e91-e101.
*Corresponding author: Sorin Uram-Tuculescu, DDS, MS, PhD, Assistant Professor, Department of Prosthodontics, School of Dentistry, Virginia Commonwealth University, USA, Tel: 804-628-3742; Fax: 804-827-1017; E-mail: suramtucules@vcu.edu

Received August 03, 2011; Accepted August 15, 2011; Published November 10 2011

Citation: Uram-Tuculescu S (2011) Esthetics and Dental Restorations. Dentistry 1:e103. doi:10.4172/2161-1122.1000e103

Copyright: (c) Uram-Tuculescu S. This is an open-access article distributed under the terms of the Creative Commons Attribution License, which permits unrestricted use, distribution, and reproduction in any medium, provided the original author and source are credited. 